\title{
LA ACTITUD FAVORABLE DE LOS EJECUTIVOS DE LAS EMPRESAS TURÍSTICAS NACIONALES FRENTE AL LIDERAZGO, COMO REQUISITO PARA SU COMPETITIVIDAD EN UN MERCADO TURÍSTICO GLOBALIZADO
}

\author{
Manuel Hernan Izaguirre Sotomayor \\ Observatorio Turístico del Perú - \\ EPTH - USMP - Lima
}

El interés por abordar el tema de la investigación, partió de seis aspectos claves:

1. Los planteamientos teóricos realizados por los más renombrados estudiosos del liderazgo y por los líderes empresariales actuales de los Estados Unidos sobre el papel del liderazgo para un futuro nuevo y audaz, donde abundan la incertidumbre y las complejidades, siendo lo único predecible: lo impredecible.

2. Las ideas y normas que han sobrevivido a su utilidad, pero tienen tanta influencia sobre el comportamiento de los ejecutivos de las empresas como si estuvieran vivas:

Henrry Ford con la producción en masa, cadena de montaje y la producción en serie (masificación del mercado), estandarización del producto.

Frederick Taylor idea de la administración como ciencia exacta, enfoque tiempo y movimiento para la eficiencia, descomposición del trabajo en unidades independientes $y$ complementarias y programadas.

Max Weber forma burocrática de la organización regida por reglamentos.

3. Los enormes cambios producidos por la globalización

La globalización ha creado interdependencia de los mercados, convirtiéndola en un solo mercado mundial que obliga a conocer al detalle su dinámica, pensar globalmente $y$ ha orientar las actividades empresariales hacia actividades de alto valor agregado que unido a la reducción de costos de producción los conviertan en empresas globalmente competitivas. Pensar sólo en función del mercado interno, es estar fuera de la tendencia actual.

Ha impuesto también el conocimiento, es decir la tecnología, como la más importante variable dentro de la función de producción global, afectando al capital, la mano de obra o ambos. Su comprensión les impone romper con los viejos paradigmas de la gestión y conducción empresarial, priorizando el activo humano como único fundamento del adecuado uso del conocimiento y la tecnología de la información, que hará posible la implementación de una obsesiva política por la calidad, que los comprometa con la tecnología, la exportación y la redistribución del ingreso como única estrategia de forjar un mundo más justo $y$ equitativo, al estar sintonizados con el nuevo paradigma de desarrollo económico que ella obliga. Es decir modernizarse para exportar y exportar para desarrollarse en un mundo globalizado que 


\section{LOS ENORMES CAMBIOS PRODUCIDOS POR LA GLOBALIZACIÓN}

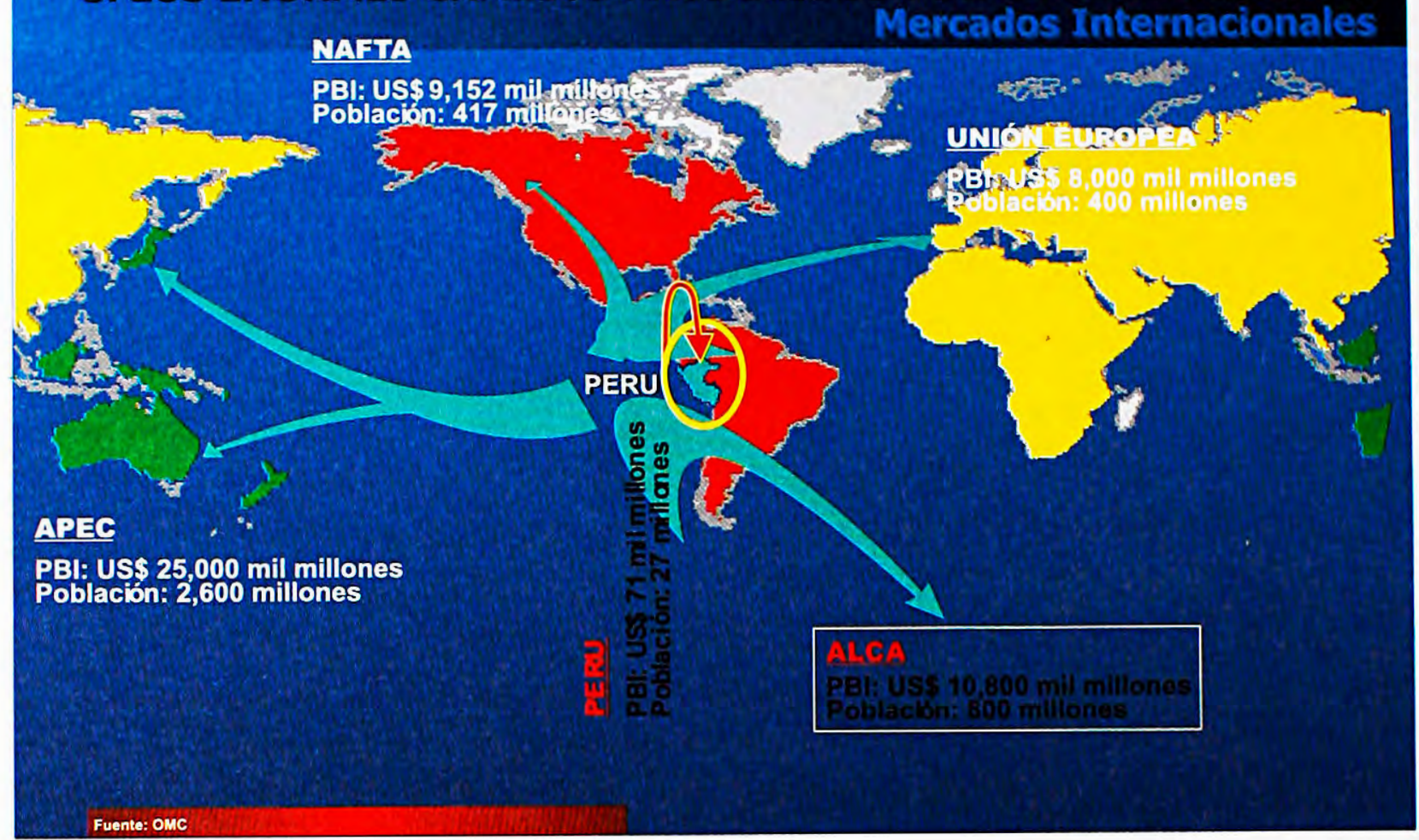

avanza inexorablemente hacia el arancel cero.

Por lo tanto la creciente competencia mundial, los trastornos económicos, políticos y sociales exigen un liderazgo completamente revolucionario que pone a prueba todos los viejos paradigmas, modos de pensar $y$ de actuar.

4. El proceso de desarrollo económico en el contexto de la globalización

Toda empresa que piense permanecer en este mundo globalizado tiene que lograr niveles adecuados de tecnología, productividad, competitividad y capacidad exportadora, para ello requiere generar excedente de capital y excelente mano de obra calificada para invertirla en la actividad más rentable y segura a largo plazo que es aumentar la capacidad exportadora.
La combinación adecuada de algunos elementos básicos como la política macroeconómica que asegure baja inflación, bajo déficit fiscal, educación, infraestructura física y mercado financiero y accionario sólido, genera la posibilidad de producir eficientemente. Pero esto sólo se logra incorporando tecnología aplicada a los procesos de producción, como punto de partida, que al asegurar un flujo constante de conocimiento, capacitación y maquinaria se pase a la segunda fase en la que la eficiencia en la producción, más la reducción de costos y las mejoras en la calidad, diseño, materiales, empaque, comercialización, gerencia, etc. hagan más productivo al país. Sólo si se combina mayor productividad y menores costos de producción se obtiene un nivel suficiente de competitividad. Todo esto para alcanzar el fin último de los procesos económicos de producción que es la redistribución del ingreso para alcanzar el 


\section{DESARROLLO ECONOMICO EN LA GLOBALIZACION}

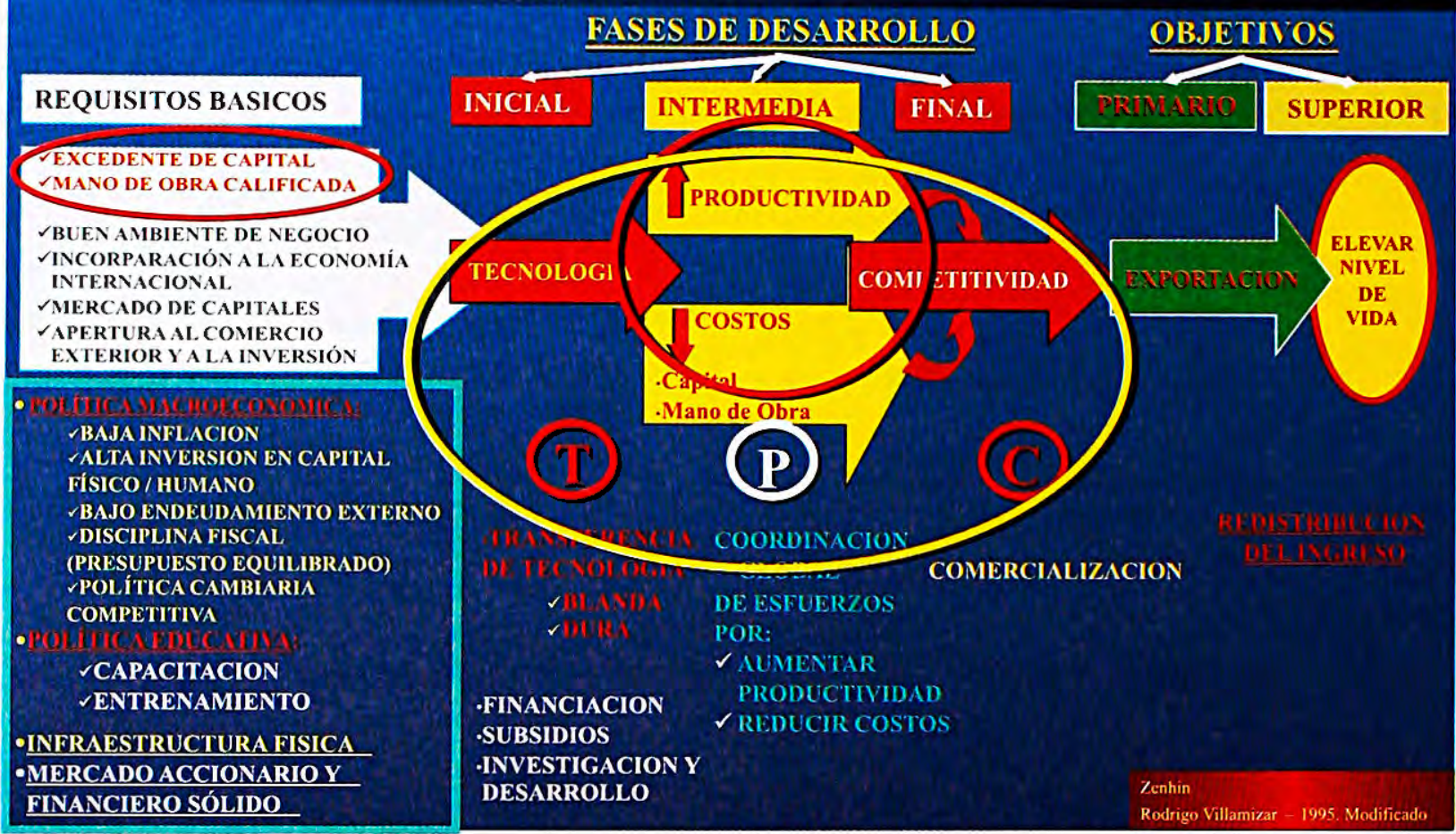

objetivo superior de elevar el nivel de vida de la población. Objetivo que se logra en el marco de la globalización a través de la exportación, toda vez que eso se logra solamente con el esfuerzo exportador del sector productivo de una nación con la fórmula tecnología, productividad $y$ competitividad.

Por lo tanto la creación de condiciones para la transferencia tecnológica, los esfuerzos para aumentar la productividad y los incrementos permanentes de competitividad sobre la base de una economía orientada a la exportación, es la receta del éxito en éste siglo XXI.

5. El impacto de la labor de los ejecutivos empresariales en la sociedad

Los ejecutivos y jefes exitosos, generan empresas exitosas, las mismas que producen servicios de calidad, generando mayor satisfacción de necesidades, empleos e ingresos que por un lado generan ahorros e inversión para producir nuevos servicios de calidad $y$ por otro lado incrementan el consumo de bienes y servicios de calidad que elevan la calidad de vida de la población

\section{Ventajas comparativas del Perú}

El Perú está considerado entre los 5 países con mayor mega diversidad del planeta, es el primero en diversidad de mariposas $y$ orquídeas, segundo en diversidad de aves, cuarto en bosques tropicales, quinto en especies de flora y fauna, es el centro mundial de endemismo y recursos genéticos, tiene 84 microclimas de las 107 existentes, posee 28 tipos de clima de los 32 que existen en el mundo, tiene una diversidad culinaria impresionante, superviven 42 grupos étnicos, 12 familias lingüísticas, 45 lenguas vivas $y$ existen 3,000 yacimientos arqueológicos.

Construir las ventajas competitivas de un país 
depende más de la voluntad colectiva y de la visión de futuro que se tenga y no de los recursos físicos y naturales con que cuenta. Es decir toda esta riqueza heredada, hay que convertirla en ventaja competitiva con el accionar de su gente, gobierno y contando con el poderoso aglutinante de una visión de futuro. No hacerlo nos impedirá ser un destino turístico líder no solo latinoamericano, sino mundial.

El presente trabajo de investigación pretende relacionar la realidad turística nacional con la carencia de un liderazgo reinventado que el mundo globalizado de hoy demanda, porque es evidente la carencia de aquellos que en base a éstos seis puntos analizados no hayan imaginado una realidad distinta y ventajosa para el turismo en el Perú.

\section{Justificación de la investigación}

La presente investigación se justifica, por la carencia de estudios previos sobre el liderazgo en turismo, por ausencia de información disponible que relacione el liderazgo con la competitividad empresarial en el sector turismo. Así mismo servirá para identificar nuevos atributos y aspectos claves del liderazgo empresarial y conocer como la globalización y la revolución tecnológica esta alterando la esencia empresarial y las destrezas para liderarla. Finalmente generará nuevas investigaciones en el área del liderazgo empresarial en el sector turismo.

\section{Descripción del problema}

El problema básicamente se caracteriza por la ausencia de una visión de futuro compartida de sector, por la persistencia de un liderazgo omnisciente, autocrático, de élite, de "mando y control", de mediciones cuantitativas, utilitarista y cortoplacista, con poca destreza para superar un ambiente reconfigurado por el cambio, la mundialización y la revolución tecnológica.

Este mercado global demanda un liderazgo reinventado, toda vez que los ejecutivos fruto de la experiencia en el puesto de trabajo, de su cargo y controlados por ideas y normas no útiles ya no califican para conducir las empresas modernas, agravadas por su resistencia a compartir el poder, desarrollar valores, integrar a diversas etnias y a la mujer a posiciones de liderazgo y considerar al recurso humano como el activo más preciado. Como telón de fondo un sistema educativo desfasado con la demanda del mercado global.

\section{Retos para un liderazgo nuevo}

El mundo globalizado de hoy demanda del ejecutivo un liderazgo nuevo centrado en conceder autoridad, responsabilidad y poder de decisión a su gente, formar y modificar constantemente su visión del mundo, dominar todas las formas de comunicación, dejar el viejo modelo de liderazgo de "mando y control", tener una imagen global del entorno de la empresa para actuar en un mundo caracterizado por la reducción de los tamaños y por el rediseño continuo. Así mismo compartir información y poder para construir confianza, ser experto en el arte de expresar con claridad una visión e inspirar a los demás con un futuro imaginado y saber extraer recursos de la mente de su gente.

\section{Núcleo básico del problema}

Conocer la actitud de los ejecutivos de las empresas turísticas nacionales frente al liderazgo y como ésta influye o determina su competitividad en un mundo turístico globalizado

\section{Tipo de estudio}

Investigación no experimental, transversal o transeccional de tipo descriptivo y correlacional puro.

\section{Objetivo general}

Identificar la actitud favorable de los ejecutivos de las empresas turísticas nacionales frente al liderazgo como requisito para su competitividad en un mercado turístico globalizado.

\section{Objetivos específicos}

1. Determinar si la actitud favorable frente al liderazgo tiene influencia en el desarrollo de la competitividad empresarial.

2. Evaluar cual de los componentes del liderazgo tiene mayor importancia en el desarrollo de la 
competitividad empresarial.

3. Analizar si existe o no diferencia de género con relación a la importancia atribuida a cada uno de los factores identificados en la generación de competitividad.

4. Analizar la existencia o no, de diferencia entre ejecutivos de distintas edades en relación con la importancia asignada a cada uno de los factores identificados.

5. Analizar la existencia o no, de diferencias entre ejecutivos de empresas turísticas consideradas en la relación de "The Perú TOP TEM 10,000 Companies - Año 2003" y los que no lo están.

\section{Población de estudio y muestra}

Población: Ejecutivos y jefes de 912 empresas turísticas listados en la Guía aérea año 40, N 458Junio 2003 y el Directorio de Hoteles selección 2003.

Muestra: 148 (912) empresas turísticas distribuidas en seis estratos:

Estrato 1: 101 (622) agencias de viaje;

Estrato 2: 13 (81) agencias mayoristas;

Estrato 3: 12 (73) empresas de hospedaje (4 hoteles de 5 estrellas, 2 de cuatro, 3 de tres, 1

Apart Hotel de tres estrellas y 2 Hostales de tres estrellas)

Estrato 4: $\quad 9$ (55) empresas de restauración

Estrato 5: 7 (43) empresas de transportación y

Estrato 6: $\quad 6$ (38) agencias tour operadores.

\section{Distribución de la muestra}

La muestra estuvo constituida por 74 ejecutivos hombres y 74 ejecutivos mujeres. Porcentualmente el mayor número de ejecutivas lo tuvieron las agencias de viaje $(63 \%)$, las agencias mayoristas ( $46 \%$ ), empresas de restauración (33\%) y agencias tour operadores $(17 \%)$, mientras que las empresas de transportación y de hospedaje no tuvieron ninguna ejecutiva mujer.
Así mismo la muestra estuvo conformada en su mayoría por ejecutivos (68\%) que jefes ( $32 \%)$, los cuales en su mayoría tenían 20 a 40 años de edad $(64 \%)$, con nivel de instrucción superior $(82 \%)$ y con 1 a 10 años de experiencia (51\%).

\section{Instrumentos utilizados para medir las variables de interés}

Los instrumentos utilizados para medir las variables de interés fueron el método de escalonamiento Líkert (escala de Líkert) y el cuestionario. Ambos instrumentos fueron auto administradas $y$ obtenidas por entrevista personal, entrevista telefónica, por correo electrónico o con respuesta diferida.

La confiabilidad del instrumento se midió con el coeficiente alfa de Cronbach aplicando el coeficiente de correlación de Pearson. La validez del instrumento de medición se estimó aplicando el método de la validez de criterio.

\section{Análisis de los resultados obtenidos}

Para facilitar el análisis de los puntajes Líkert obtenidos se construyó una gráfica con una escala del 1 al 5.

Los puntajes del 1 al 2.99 expresa una actitud negativa o desfavorable, el puntaje 3 expresa una actitud indiferente y los puntajes del 3.1 al 5 expresa una actitud positiva ofavorable.

Sin embargo, para facilitar la interpretación de los puntajes obtenidos en la Escala de Líkert se determinó que los puntajes comprendidos entre 3.1 a 3.67 expresaran una actitud bajamente favorable; de 3.68 a 4.33 actitud medianamente favorable y puntajes de 4.34 a 5.00 actitud muy favorable.

De igual manera para puntajes entre 2.99 a 2.33 expresaron una actitud bajamente desfavorable; de 2.32 a 1.67 actitud medianamente desfavorable y puntajes de 1.66 a 1 actitud muy desfavorable. Ver gráfico $\mathrm{N}^{\circ} 1 \mathrm{a}$. 
Gráfico No 1a

ESCALA GRAFICA PARA EL ANALISIS E INTERPRETACION DE LOS VALORES OBTENIDO EN LA ESCALADE LIKERT POR LOS EJECUTIVOS Y JEFES DE LAS EMPRESAS TURISTICAS

Provincias: Lima y Callao

Junio del 2004

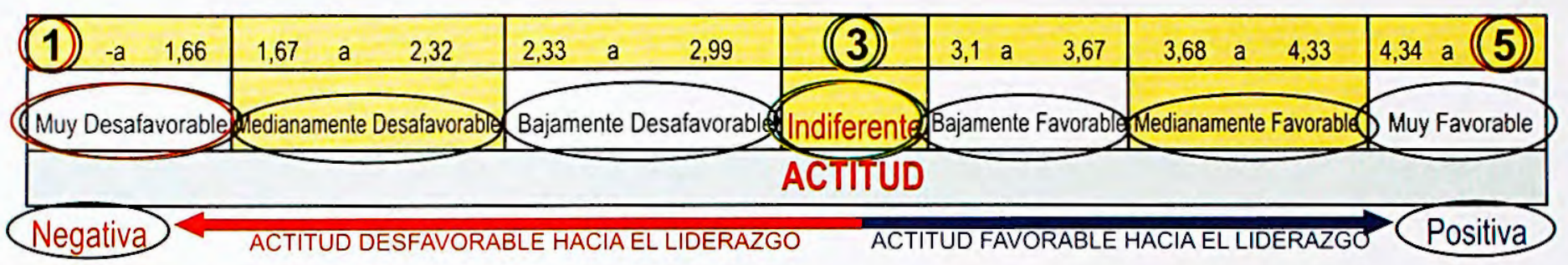

Valor obtenido en la Escala de Líkert, por tipo de empresa para ejecutivos y jefes de las empresas turísticas de Lima y Callao

Los resultados de la presente investigación, ponen de manifiesto que todos los ejecutivos (Presidentes de Directorio, Directores, Gerentes Generales y Gerentes) y jefes que dirigen las empresas turísticas nacionales, si bien es cierto que tienen una actitud favorable hacia el liderazgo, ésta es sólo medianamente favorable, cuando el mundo actual donde desarrollan sus actividades gerenciales y directrices reclama una actitud muy favorable hacia el liderazgo, así como poseer características y atributos de liderazgo que le permitan enfrentar con éxito los cambios turbulentos e impredecibles del mundo globalizado, es decir deben adquirir una forma de liderar sus empresas completamente nueva, si desean convertirse en empresas globales y por ende ser altamente competitivas.

Sin embargo al comparar esta actitud medianamente favorable hacia el liderazgo de los ejecutivos y jefes, según el tipo de empresa donde laboran, se observa que los ejecutivos y jefes de las Empresas de transportación, tuvieron una actitud muy favorable hacia el liderazgo, comparado con la actitud medianamente favorable de los ejecutivos y jefes de las empresas de hospedaje, agencias de viaje mayoristas, empresas de restauración, agencias tour operadores y agencias de viaje.
Los ejecutivos y jefes de las agencias de viaje estuvieron muy cerca a tener una actitud poco favorable hacia el liderazgo.

Valor obtenido en la Escala de Líkert, por número de estrellas para ejecutivos y jefes de las empresas de hospedaje de Lima y Callao

Así mismo la actitud hacia el liderazgo de los ejecutivos y jefes de las empresas de hospedaje varió según la categoría de empresa hotelera que conducen.

Asi, los ejecutivos y jefes responsables de hoteles de 5 estrellas tenían una actitud muy favorable y los que dirigían hoteles de 4 estrellas, hostales, Apart hotel y hoteles de 3 estrellas tuvieron una actitud medianamente favorable hacia el liderazgo, correspondiéndole a los ejecutivos y jefes de los hoteles de 3 estrellas una actitud muy cercana a poco favorable hacia el liderazgo.

Valor obtenido en la Escala de Líkert, por sexo y cargo para ejecutivos $y$ jefes de las empresas turísticas de Lima y Callao

Cuando la actitud hacia el liderazgo de los ejecutivos y jefes de las empresas turísticas de la muestra, es analizada según el sexo, se observa que la actitud hacia el liderazgo de los ejecutivos y jefes de ambos sexos fue medianamente favorable. 
De igual manera, al ser analizada desde la perspectiva del cargo ocupado, se aprecia que el Presidente de Directorio (ejecutivo de sexo masculino) tuvo la actitud muy favorable hacia el liderazgo, mientras el Director (Ejecutivo de sexo femenino) tuvo una actitud poco favorable hacia el liderazgo.

La actitud hacia el liderazgo de los demás directivos que ocupan los otros cargos fue medianamente favorable hacia el liderazgo. Dentro de éste rango de medianamente favorable, los Gerentes, de sexo femenino tuvieron una actitud hacia el liderazgo más favorable que los Gerentes de sexo masculino; mientras que los Gerentes Generales masculinos lo fueron más que los Gerentes Generales femeninos.

\section{Valor obtenido en la Escala de Líkert, por rango de edad para ejecutivos $y$ jefes de las empresas turísticas de Lima y Callao}

Al correlacionar la actitud hacia el liderazgo con la edad de los ejecutivos y jefes de las empresas turísticas, se evidencia que todos los grupos de edad tuvieron una actitud medianamente favorable hacia el liderazgo, correspondiéndole en este rango de medianamente favorable, a los directivos con edades comprendidas en el rango de 41 a 50 años de edad la actitud más favorable, mientras los mayores de 51 años tuvieron la actitud menos favorable hacia el liderazgo.

Sin embargo la tendencia de los puntajes obtenidos en la Escala Líkert por los ejecutivos y jefes de las empresas turísticas, agrupados en los rangos de edad especificados, muestra una pendiente negativa a medida que la edad promedio avanza.

Sin embargo la tendencia de los puntajes obtenidos en la Escala Líkert por los ejecutivos y jefes de las empresas turísticas, agrupados en los niveles de instrucción y en rangos de años de experiencia especificados, muestra una pendiente positiva a medida que el nivel de instrucción avanza y acumulan años de experiencia.
Uso de la tecnología de la información por las
empresas turísticas presentes y ausentes en el
ranking de competitividad en Perú TOP TEM
10,000 companies, año 2003 por estrato

El mundo globalizado de hoy demanda el uso de la tecnología de la información, de las supercarreteras, de las redes telemáticas, de realidad virtual y de los procesos y materiales inteligentes para lograr competitividad. Hacerlo obliga contar con trabajadores con actitud flexible y receptiva a los cambios tecnológicos y a las innovaciones. Sin embargo al comparar el tipo de tecnología de la información utilizada por las empresas turísticas presentes ( $18 \%$ / 26 empresas) vs. las ausentes ( $82 \%$ / 122 empresas) en el Perú TOP TEM 10,000 companies Año 2003 según estrato, se evidencia que el $100 \%$ de las empresas presentes y ausentes, contaban con línea telefónica. De los presentes, el $97 \%$ (25) tenían un fax en sus oficinas, comparados con el 95\% (116) ausentes. Así mismo el 88\% (23) de las empresas presentes y el $94 \%$ (115) de las ausentes tenían correo electrónico. Finalmente el $46 \%$ (12) de las empresas presentes tenían una página Web, comparado con el $38 \%$ (46) de las ausentes que no la tenían.

\section{Competitividad global de las empresas turísticas}

De las 26 empresas presentes en el ranking de competitividad "The Perú TOP TEM 10,000 Companies Año 2003" ninguna empresa turística califica para ser considerada competitiva a nivel global por no tener un ejecutivo o jefe con una actitud muy favorable en el $80 \%$ de las afirmaciones sobre aspectos o características claves del liderazgo para el siglo XXI, responder con un sí, siempre o nunca, cuando corresponda, en el $80 \%$ de las afirmaciones sobre las actividades claves donde debe ejercer su liderazgo y se identifique mucho con el $80 \%$ de los atributos de liderazgo mencionados, siendo consideradas, las 26 empresas presente, como empresas turísticas competitivas solo a nivel nacional o local. 
Características de liderazgo en los ejecutivos de las empresas turísticas nacionales

En cuanto a las características de liderazgo abordaremos solo aquellas características que los líderes entrevistados, en un porcentaje apreciable, no estuvieron de acuerdo ni en desacuerdo o estuvieron muy en desacuerdo hacia características consideradas fundamentales para un liderazgo reinventado que enfrente con éxito el cambio constante e impredecible que el mundo globalizado demanda.

Casi un tercio $(27 \%)$ de los ejecutivos entrevistados fueron indiferentes o no se identificaron con la característica del liderazgo: "influir sobre las personas para que propicien un clima de confianza" a pesar que en el contexto de la globalización, es importante construir una cultura empresarial de libertad, participativa, inspiradora, creativa y sensible con la responsabilidad descentralizada y participación del poder.

La complejidad empresarial en aumento, exige no una actitud medianamente favorable hacia la construcción de un clima organizacional de confianza, sino demanda una actitud muy favorable para asumir plenamente la responsabilidad de su construcción, que demanda un cambio genuino en el comportamiento del líder y la incorporación de nuevos procesos y hábitos organizacionales. Es aquí donde el ejecutivo debe hacer lo que dice que hará.

Igualmente el $29 \%$ fueron indiferentes o no se identificaron con la característica del liderazgo: "fomentar la innovación y alentar a la gente a perfeccionar sus conocimientos y habilidades" aún sabiendo que las empresas fueron diseñadas para un mundo que ya no existe, asegurando que nunca se cometieran equivocaciones, resultando costoso, muy inhibidor, poco creativo, contrapuesto a todo lo que la globalización está obligando a los ejecutivos a aprender, a innovar y a operar más eficientemente y con más calidad y excelencia para poder competir con éxito en el mercado mundial. Para participar con eficacia en las diferentes configuraciones competitivas $y$ mundiales, es imperativo generar una fuerza laboral más inteligente.

Es más crucial la actitud indiferente o negativa de los ejecutivos de las empresas turísticas con la característica del liderazgo: "difundir y mantener un sueño a otros generando una visión común". Cuando ésta se refiere a su percepción personal como líder sólo el $34 \%$ esta muy de acuerdo y el $17 \%$ tiene una actitud indiferente o negativa.

Pero cuando lo refiere a la percepción que tiene de los líderes de empresas nacionales un preocupante $41 \%$ de ejecutivos refiere que son indiferentes o tienen una actitud negativa frente a la visión, a pesar que en la comunidad mundial, compleja e interdependiente cada líder empresarial administrará mediante la visión, por que ella guía sus objetivos, sus estrategias, sus actividades $y$ escoge sus decisiones, usándola como fuerza unificadora y como rumbo, necesitando imprescindiblemente, un itinerario de una cultura basada en valores, que sean las piedras que guíen sus decisiones y acciones.

Los ejecutivos y jefes de las empresas turísticas nacionales necesitan decididamente una actitud muy favorable hacia la visión y misión empresarial para tener una de las destrezas de liderazgo orientada al futuro: ser capaces de imaginar un futuro más brillante, tan lleno de interesantes posibilidades que nadie sea capaz de descansar hasta lograrlos, por que tienen que ser capaces de expresar una visión puente que une a las personas con el futuro.

Más de la cuarta parte $(26 \%)$ de los ejecutivos tienen una actitud indiferente o negativa hacia el "otorgar recursos necesarios para lograr objetivos empresariales", aún sabiendo que solo se logrará el éxito empresarial y personal intentando alcanzarlos implacablemente. Solo el $30 \%$ estuvieron muy de acuerdo en otorgar recursos para su logro.

Solo el $23 \%$ manifestó estar muy de acuerdo en estar interesado por "supervisar directamente las 
actividades encomendadas", mientras que el $27 \%$ mostraban indiferencia o una actitud negativa, a pesar que el mundo turbulento de cambios imprevisibles en que desarrollan sus actividades empresariales les exige averiguar más mediante el seguimiento, por que los líderes del futuro tendrán que cambiar y crecer en el puesto de trabajo. Realizar el seguimiento continuo es importante para que los ejecutivos y jefes crezcan de una manera que produzca un efecto positivo $y$ mensurable, asegurando a través del seguimiento la puesta en práctica efectiva de sus decisiones al crear la tensión constructiva que lleva en el largo plazo, al cambio y mejora continua.

El $31 \%$ estuvieron muy de acuerdo con interesarse por "la justicia al aplicar las recompensas $y$ sanciones", frente la $28 \%$ que mostraron indiferencia o una actitud negativa a pesar que los ejecutivos de las empresas turísticas del Perú dedican una cantidad considerable de tiempo a intentar influir en los resultados económicos, a menudo a través de un cambio en la estructura organizacional y el desarrollo de una cultura empresarial coherente con los valores y principios organizacionales, y que reconozcan y promuevan los comportamientos deseables y castiguen los comportamientos no deseables siendo justos al aplicarlas.

El $22 \%$ de los ejecutivos estuvieron muy de acuerdo con interesarse por "imitar todo lo bueno de la competencia mejorándolo o innovándolo", mientras que el $39 \%$ mostraron una actitud indiferente o negativa a pesar que en el mundo globalizado de hoy, los ejecutivos requieren instaurar en las empresas que dirigen un proceso sistemático y continuo de investigación para evaluar los productos, servicios y procesos de trabajo de las empresas reconocidas como representantes de las mejores prácticas con la finalidad de realizar mejoras empresariales.

Hecho que produce información que ayuda a tomar decisiones a todos los que están facultados para tomarlas, convirtiéndose en instrumento fundamental para guiar a los trabajadores $y$ directivos hacia el proceso de analizar el exterior en busca de ideas e inspiración.

Sólo el $14 \%$ de los ejecutivos entrevistados precisó estar muy de acuerdo con interesarse por "reducir el tamaño de sus empresas para hacerlas más competitivas", comparado con el $72 \%$ que mostraron una actitud indiferente o negativa a una práctica que se generaliza cada vez con mayor rapidez e intensidad en las empresas de éxito, impulsados por la realidad del mundo en que viven, caracterizado por la reducción del tamaño empresarial y por el rediseño continuo, dependiendo para la realización de sus actividades y necesidades esenciales o estratégicas de su personal a tiempo completo y para el resto abastecerse del exterior o emplear sub contratistas, por que para ser competitivo necesita lograr que se trabaje más y con mayor rapidez, y que eso se consiga con un staff de apoyo considerablemente menor, toda vez que las actividades de producción y apoyo están cada vez más disperso y parcelado entre distintas empresas u organizaciones (outsoursing).

Así mismo las empresas de éxito, actualmente se han desprendido de actividades importantes, pero no esenciales en un afán de buscar mejorar los resultados y reducir los costes unitarios y mejorar la realización del servicio, logrando mayor competitividad.

\section{Principios básicos y liderazgo en las empresas turísticas nacionales}

Cuando se refiere a los principios básicos, especialmente a la Visión como la capacidad de transmitir su sueño a otros generando un propósito común, solo el $34 \%$ refirió estar muy de acuerdo con el enunciado, mientras el $17 \%$ mostró una actitud indiferente o negativo, a pesar que la actitud para el conjunto de los directivos, "hacia transmitir un sueño a otros, generando una visión común" fue medianamente favorable, con excepción de los directivos que conducen las agencias tour operadores cuya actitud fue bajamente favorable. Sin embargo al referirse específicamente a la actitud, de los ejecutivos que 
conducen empresas turísticas nacionales, fue una actitud medianamente favorable en los directivos que dirigen agencias de viaje y empresas de transportación y bajamente favorable en todos los demás.

En cuanto a la confianza generada en la empresa, gracias a la "capacidad de compartir información $y$ poder" el $27 \%$ de los ejecutivos estuvieron muy de acuerdo y un $27 \%$ mostró una actitud indiferente o negativa a pesar que el empowerment saca lo mejor de cada trabajador, les inspira para alcanzar resultados extraordinarios, liberando su energía creadora y permitiéndoles ser todo lo que son capaces de ser.

Las empresas turísticas, en el siglo XXI, tienen que desarrollar una nueva cultura de desempeño que dependa de redes interactivas más rápidas y flexibles de personas comprometidas (equipos) a las que se les han concedido facultades (autoridad) para la rápida toma de decisiones para servir al cliente y producir resultados empresariales, facilitando el surgimiento de más líderes dentro de las empresas.

Crear la energía necesaria que inspire a los trabajadores a prever y responder a gran velocidad, implica que los ejecutivos tengan una actitud decididamente muy favorable hacia la delegación del poder de decisión, para impedir que las reglas sustituyan al pensamiento, las reuniones a la acción y los procedimientos a la responsabilidad.

Referido al aprendizaje en el aspecto puntual: "capacidad de conocerse a sí mismo, ser consciente de sus fortalezas y debilidades para adecuarse a las nuevas circunstancias", solo el $19 \%$ de ejecutivos estaban muy de acuerdo, mientras que el $34 \%$ eran indiferentes o negativos ignorando que proporcionar liderazgo en un entorno empresarial turbulento y rápidamente cambiante, implica desarrollar destrezas empresariales, de liderazgo y de eficacia personal, así como dominar el arte de formar equipos, aprender a trabajar con ellos y hacer lo que ha dicho que hará.
El líder debe actuar para convertir las aspiraciones en hechos, requiriendo credibilidad personal y aptitud organizacional, sirviéndose de los corazones (emoción), de las mentes (cogniciones) y pies y manos (acción) de sus empleados.

Estos supuestos obligan a los líderes empresariales aprender, desaprender y volver a aprender continuamente, evidenciando que los empresarios turísticos que carecen de flexibilidad mental necesaria, para pensar más allá de las fronteras, les resultará cada vez más difícil mantenerse y prosperar en el mercado actual.

El $23 \%$ de los ejecutivos estaban muy de acuerdo con la "conciencia del poder de la diversidad y lo negativo de la parcialidad", frente al $21 \%$ de los ejecutivos que eran indiferentes o tenían una actitud negativa a pesar que es clave que los líderes estén dispuestos a aceptar, entre otras exigencias del mundo globalizado, hacerse más sensibles y comprensivos con las diferencias étnicas, culturales y de sexo dentro del lugar de trabajo demostrándolo en sus decisiones gerenciales al respetar y honrar la diversidad de los trabajadores, como la forma más eficaz de reforzar el trabajo en equipo, convirtiéndola en ventaja competitiva para el siglo XXI, al equilibrar el liderazgo masculino y femenino.

Definitivamente la mujer ha cambiado de una manera constructiva la faz del liderazgo, la cultura y la organización en todos los sectores, generando una nueva sociedad que aprecia todas las etnias sin distingos entre los sexos e impulsando el surgimiento de nuevos modelos de liderazgo con mayor tolerancia y flexibilidad.

Todos los ejecutivos y jefes que dirigen empresas turísticas nacionales tienen una actitud medianamente favorable hacia ser consciente del poder de la diversidad y de lo negativo de la parcialidad, con excepción de los directivos con nivel media o secundaria que tienen una actitud bajamente favorable y de los que dirigen empresas de transportación que tienen una actitud muy favorable. 
Solo el $18 \%$ de los ejecutivos estaban muy de acuerdo con "valorar la diversidad, la integridad, la responsabilidad personal, la fortaleza del trabajo en equipo y el compromiso con el grupo", a diferencia del $24 \%$ de ejecutivos que eran indiferentes o tenían una actitud negativa, a pesar que los directivos reconocen que los años por venir exigirán, por un lado manejar porciones cada vez mayores del planeta y por otro, tener la capacidad para conceptuar visiones globales amplias que abarquen $y$ hagan honor a la rica diversidad de toda la gente y del planeta, facultando a sus trabajadores para actuar sobre ella. Así mismo la globalización les obliga a aprender, innovar y operar más eficientemente y con más calidad y excelencia para poder competir con éxito en el mercado mundial, toda vez que lo único que tiene que ofertar es valor. Por tanto, es necesario comprometer a todos los cerebros de la empresa, por que la cultura que sustenta la excelencia debe crearse alrededor del imperativo de la calidad y servicio al cliente, convirtiéndolo en su mayor ventaja competitiva al estar directamente relacionado con la satisfacción de los empleados, la lealtad y la productividad resultante. Para el liderazgo moderno los valores corrientes son el empowerment, la visión, los valores, la cultura, la calidad y el servicio.

La actitud hacia reconocer la fortaleza del trabajo en equipo y el compromiso con el grupo en los ejecutivos que dirigen las empresas de transportación, restauración y de hospedaje, fue muy favorable, frente a los directivos que conducen agencias de viaje, tour operadores $y$ mayoristas que tuvieron una actitud medianamente favorable.

El único ambiente que llevará hacia logros creativos e innovadores se fundamenta en la integridad y en la confianza, haciendo necesario que las relaciones y la comunicación en toda la empresa sean confiables, abiertas y honestas, constituyéndose en el corazón de la ética y de la integridad, haciendo trascendente el trabajo que realizan al convertir objetivos en realidades. Así mismo le obliga reinventarse a sí mismos y a las empresas que dirigen, para enfrentar con éxito los retos que el mundo globalizado les exige, generando a medida que las rediseñan mayores oportunidades para el surgimiento de los líderes en medio de la empresa y no en la cumbre de la jerarquía empresarial.

Al abordar la responsabilidad social en el sentido de "administrar el entorno natural y ser capaz" el $22 \%$ de los ejecutivos refirieron estar muy de acuerdo y el $27 \%$ eran indiferentes o tenían una actitud negativa, aún sabiendo que el entorno actual exige poseer la imaginación para crear empresas que conserven el medio ambiente, posibilitando tener una economía sostenible.

Los ejecutivos tendrán que prestar atención a las cuestiones sociales de la protección del ambiente y del planeta, de la creación de una sociedad más justa, así como atender el creciente interés por una educación de diferente calidad que prepare a los trabajadores para que no sigan haciendo su trabajo diario, sino hagan lo que es necesario hacer, toda vez que los recursos ya no son los que se extraen del suelo, sino los que provienen de sus mentes, exigiendo un liderazgo tan completamente revolucionario que pone a prueba sus viejos paradigmas, sus modos de pensar y de actuar.

Sin embargo, en todo el mundo, las empresas abordan el siglo XXI con un grave déficit de líderes empresariales equipados para hacer frente a las complejidades, la volatilidad y las nuevas reglas del mercado mundial que obliga a las empresas a revisar sus opciones estratégicas, a redefinir sus prioridades, a aprender maneras completamente nuevas de hacer las cosas o de comunicarse entre sí. Así mismo los cambios tecnológicos, económicos, político, socioculturales y competitivos fuerza utilizar la tecnología como arma competitiva para la conquista de los mercados en un mundo donde el cambio, la inestabilidad y la impredecibilidad son las constantes principales, obligando a los ejecutivos a pensar, como artífices del cambio, adquiriendo nuevos conceptos y destrezas, así como desaprendiendo las cosas que ya no son útiles para la empresa. 
La competencia global, la complejidad creciente, la velocidad del cambio y la desaparición de la jerarquía y del "poder de la posición" obliga a los ejecutivos a aprender, a innovar, a operar más eficientemente y con más calidad y excelencia sus empresas, a usar nuevas tecnologías para el liderazgo, como el empowerment, la calidad, la visión, el servicio al cliente, los valores compartidos, la cultura, los equipos autodirigidos, la reingeniería, el downsizing (reducción del tamaño de las empresas), el benchmarking y las estrategias globales.

También les demanda capacidad para reconocer que sus empresas dependen no sólo de sus propias organizaciones, sino también de la salud del entorno en el cual operan, comprendiendo que empresa, directivos y trabajadores son parte de una red vital, global e interconectada que lleva a eliminar capas de jerarquía y funciones, en una feroz competencia para lograr velocidad $y$ flexibilidad.

\section{ATRIBUTOS DE LIDERAZGO EN LOS EJECUTIVOS DE LAS EMPRESAS TURÍSTICAS NACIONALES}

El $68 \%$ de los ejecutivos tenían mucha identificación con el atributo "concentración en la persona", mientras el $32 \%$ se identificaron poco o no se identificaron con el atributo $(21 \%$ no lo mencionaron), a pesar que los empresarios exitosos han focalizado su atención en la educación porque sin una fuerza laboral bien educada, no tendrán éxito, agravado por la formación de los líderes potenciales para las exigencias de una época diferente e inexistente.

Al moverse la información en tiempo real, es necesario que los líderes eficaces tengan una actitud muy favorable hacia el conocimiento $y$ aprendizaje para formar y modificar constantemente su visión del mundo, para continuar aprendiendo y creciendo. De lo contrario quedaran desfasados en este mundo cambiante que obliga aprender y desaprender, a mejorar la educación, tener una fuerza de trabajo más inteligente y maximizar el talento, la creatividad y todo el potencial de sus trabajadores para alcanzar estándares de desempeño de clase mundial.

Sólo el $26 \%$ de los ejecutivos se identificaron mucho con el atributo "desobediencia a lo establecido o formal", mientras que el $74 \%$ se identificaron poco, no se identificaron o no lo mencionaron, aún sabiendo que sólo el que desobedece lo establecido y formal, es el que encontrará nuevas formas de conducir sus empresas, que fueron diseñadas para un mundo que ya no existe, asegurando que nunca se cometan equivocaciones, resultando costoso, muy inhibidor, poco creativo, a pesar que la globalización les demanda aprender, crear nuevos caminos, determinar nuevos enfoques para los viejos problemas, innovar, y operar más eficientemente, con más calidad y excelencia para poder competir con éxito en el mercado mundial. Lograrlo implica reinventarse a sí mismos y a sus empresas, para enfrentar con éxito los retos que el mundo globalizado les exige, generando a medida que las empresas se rediseñan mayores oportunidades para el surgimiento de los líderes en medio de la empresa y no en la cumbre de la jerarquía empresarial.

El $70 \%$ de los directivos respondieron tener mucha identificación con el atributo "intentar $/ o$ imposible", frente al $30 \%$ que no lo mencionaron, no se identificaron o se identificaron poco, a pesar que en el mundo globalizado de hoy demanda a las empresas turísticas contar con líderes que tengan el valor de atreverse a correr riesgos audaces y tener la voluntad de correrlos, creen nuevos caminos, determinen nuevos enfoques para los viejos problemas, así como la humildad para reconocer sus errores y aprender de ellos, ayudando a sus subordinados y a la empresa a aprender del fracaso, por que saben que su penalización desalienta la iniciativa y la asunción de riesgos.

Sólo el $53 \%$ se identificaron mucho con el atributo "pensar en el largo plazo", frente al $47 \%$ que no lo hizo, a pesar que el mundo globalizado de hoy demanda líderes que tengan visión, valores $y$ creencias firmes que impulsen sus actos Así mismo, 
con sus maneras inimitables, inspiren confianza, sean personalmente creíbles, acaben con la desesperación, combatan el miedo, inicien acciones positivas y productivas, proyecten luz, definan los objetivos y describan futuros más brillantes.

El $41 \%$ de los ejecutivos referían no identificarse con el atributo "preguntar quién y por qué", frente al $59 \%$ que si lo hacían, porque le permite saber quienes tienen iniciativas y las razones por las que hacen las tareas. Así mismo para hacer que los empleados vean y sientan que la dirección está centrada, que presta atención y se preocupa, según lo demuestra la persistencia del seguimiento, para crear una clase de tensión constructiva que propicie el cambio a largo plazo y la mejora continua.

Sólo $53 \%$ se identificaron mucho con el atributo "soñar", el $47 \%$ no se identificaron, existiendo un $20 \%$ de ejecutivos que no la mencionaron, a pesar que los líderes deben ser capaces de imaginar lo que parece imposible en las presentes circunstancias y reclutar a otros para hacer que sea una realidad, por que tienen que ser capaces de expresar un futuro tan lleno de interesantes posibilidades que nadie sea capaz de descansar hasta lograrlos.

Igualmente $56 \%$ se identificaron con el atributo "utilizar el hemisferio cerebral derecho" lugar del cerebro donde radica la creatividad, la imaginación, la parte humana y lo fundamental de la inteligencia emocional, frente al $44 \%$ que no se identifican, a pesar que los ejecutivos de las empresas turísticas del Perú dedican una cantidad considerable de tiempo a intentar influir en los resultados económicos, a menudo a través de un cambio en la estructura organizacional, sin centrar casi su atención en la influencia que ejercen en la cultura organizacional generando una cultura de valores compartidos donde se escogen $y$ configuran nuevas reglas "no escritas" articulándolas, claramente, hace que todos las llevan a cabo y todos sean recompensados.

Sin embargo no existe ningún sustituto del compromiso para originar un cambio profundo si no se hace nada para alentar la responsabilidad individual. Nadie puede forzar a otra persona a aprender si el aprendizaje implica cambios en las convicciones $y$ actitudes $y$ nuevos modos fundamentales de pensar y actuar, más aún si dichos cambios no modifican la cultura empresarial basada en el temor y en las actitudes defensivas.

El $64 \%$ se identificaron mucho con el atributo "vender un sueño anidándolo en la mente y el corazón" de su gente, frente a un $36 \%$ que no se identificaron, sabiendo que el sentimiento que evoca la visión es más importante que la lógica que la sustenta. Cuando la visión se analiza día a día, se repite, se recrea y se renueva por el compromiso, entonces mueve $y$ estimula a las personas hacia su realización. Comienzan de verdad a "vivir la visión" y ser realidad.

Si el ejecutivo que dirige una empresa turística no actúa de acuerdo con una visión, no influirá intencionadamente en sus trabajadores y en las condiciones en las que trabajan, no permitirá la realización de todas sus posibilidades ni logrará hacer realidad la visión, ni maximizará el desarrollo organizacional y personal de toda la plana ejecutiva y de sus trabajadores, evidenciando que las empresas turísticas necesitan visionarios creadores.

El $57 \%$ se identificaron con el atributo "visión conceptual", frente al $43 \%$ que no se identificaron ( $30 \%$ no lo mencionaron), a pesar de ser el eje central de la efectividad fijando la orientación, motivando eficazmente $y$ dando empowerment a la gente, por que si las personas no tienen un cuadro definitivo de la situación a la cual se quiere llegar (visión), no podrán ser responsables, ni tampoco tomar decisiones efectivas. En cambio cuando todos están motivados por una visión común, tienen una gran unidad de propósito, inspiración y empuje hacia delante. Las personas se auto dirigen y producen dentro del contexto de una visión con poder, tienen mucho más que ofrecer a la empresa, por que es a través de una visión clara que el empresario turístico logrará lo mejor de sus trabajadores. 


\section{VALORES COMPARTIDOS $Y$ LIDERAZGO EN LOS EJECUTIVOS DE LAS EMPRESAS TURÍSTICAS NACIONALES}

Aproximadamente $72 \%$ de directivos integrantes de la muestra mencionaron algún valor empresarial compartido, frente al $28 \%$ de directivos que no mencionaron ningún valor empresarial. Así mismo, 33\% de los directivos de las empresas de restauración y $31 \%$ de las agencias de viaje y de agencias mayoristas no mencionaron valor empresarial compartido alguno, correspondiéndole a los directivos de las empresas de transportación la más alta proporción de directivos que lo hicieron ( $86 \%$ ).

Cabe mencionar que los valores que más frecuentemente fueron mencionados por los directivos tuvieron una frecuencia de mención muy pobre de 25 menciones y solo $8 \%$ de directivos lo expresaron. Los valores empresariales que más se mencionaron fueron en orden de frecuencia de mayor a menor: calidad de servicio (25 menciones, $8 \%$ de directivos lo mencionaron), honestidad $(22 / 7 \%)$, servicio al cliente $(20 / 6 \%)$, respeto $(18 / 6 \%)$, honradez $(17 / 5 \%)$, responsabilidad $(17 / 5 \%)$, trabajo en equipo $(17 / 5 \%)$, lealtad $(13 / 4 \%)$, puntualidad $(13 / 4 \%)$, compañerismo $(12 / 4 \%)$, confianza $(11 / 4 \%)$ y clima institucional adecuado $(9 / 3 \%)$.

Construir o reconstruir la cultura organizacional requiere el redescubrimiento de la necesidad de definir, dar forma y utilizar los valores fundamentales, comúnmente mantenidos en las empresas, por que el consenso basado en los valores crea compromiso acerca de dónde va la empresa y de cómo se consigue llegar allí.

Es responsabilidad de los ejecutivos serios, marcar la pauta para una cultura basada en valores, toda vez que ésta, no es, solo un conjunto de valores compartidos, sino más bien la interconexión e integración de éstos con las operaciones empresariales. El reto verdadero no se encuentra en la simple articulación de valores y en colgar una placa en la pared, sino en la manera de hacer que verdaderamente esos valores tengan vida. Serlo implica tener hábitos, valores, rasgos y aptitudes personales para ser personalmente creíble, engendrar confianza y compromiso de aquellos que han de seguir su dirección.

PERFIL COMPARADO DEL LÍDER DE LAS EMPRESAS TURÍSTICAS NACIONALES PRESENTES Y AUSENTES EN PERÚ TOP TEM 10,000 COMPANIES AÑO 2003

Cuando comparamos el grado de la identificación hacia los atributos de liderazgo entre las empresas presentes y ausentes en el Perú TOP TEM 10,000 companies se aprecia que las empresas presentes tuvieron marcada mayor identificación que las empresas ausentes hacia cuatro atributos: hacer lo que debe hacerse $(85 \%$ vs. $70 \%)$, inspirar confianza ( $96 \%$ vs. $87 \%$ ), pensar en el largo plazo (62 vs. 52 ) y soñar (65\% vs. 50 ). Las empresas ausentes lo tuvieron hacia cuatro atributos: desarrollar nuevos caminos $(75 \%$ vs. $65 \%)$, desobediencia a lo establecido o formal ( $27 \%$ vs. $15 \%)$, planear lo que se ejecutará ( $85 \%$ vs. $77 \%$ ) y utilizar el cerebro derecho (60\% vs. $38 \%$ ).

Cuando se compara la actitud de los ejecutivos de las empresas presentes vs. las ausentes en el Perú TOP TEM 10,000 companies del año 2003, hacia las 32 áreas de acción del liderazgo consideradas, solo tuvieron una diferente actitud hacia cuatro áreas de acción: hacia reducir el tamaño de sus empresas para hacerlas más competitivas, correspondiéndole a los ejecutivos presentes una actitud bajamente desfavorable, mientras que los ejecutivos de las empresas ausentes tuvieron una actitud medianamente favorable. Hacia supervisar directamente las actividades encomendadas a sus trabajadores, los ejecutivos de las empresas presentes tuvieron una actitud bajamente favorable, mientras que los ejecutivos de las empresas ausentes tuvieron una actitud medianamente favorable. La actitud de los ejecutivos presentes hacia cuestionar sus decisiones, aprender de los errores y celebrar el éxito de los demás y aceptar los talentos individuales fue muy favorable, frente a la de los ejecutivos de las empresas ausentes que fue medianamente favorable. 


\section{CONCLUSIONES DE LA INVESTIGACIÓN}

Las conclusiones de la presente investigación son las siguientes:

1. La actitud hacia el liderazgo de los ejecutivos y jefes de las empresas turísticas, en conjunto, fue medianamente favorable.

2. Los directivos de las empresas de transportación, tuvieron una actitud muy favorable hacia el liderazgo, comparado con los demás estratos que tuvieron una actitud medianamente favorable.

3. Los ejecutivos y jefes de hoteles de 5 estrellas tenían una actitud muy favorable hacia el liderazgo, mientras los que dirigían hoteles de 4 estrellas, hostales, Apart hotel y hoteles de 3 estrellas tuvieron una actitud medianamente favorable.

4. La actitud hacia el liderazgo de los directivos según sexo, instrucción y experiencia no evidenció diferencias correspondiéndoles una actitud medianamente favorable.

5. La actitud hacia el liderazgo, en el rango de medianamente favorable, fue menos favorable a medida que aumentaba la edad de los directivos, siendo más favorable a medida que el nivel de instrucción y los años de experiencia aumentaba.

6. La edad y la experiencia no estuvieron correlacionados linealmente con la actitud hacia el liderazgo.
7. Ninguna de las 26 empresas presentes en el ranking de competitividad calificó para ser considerada competitiva a nivel global, siendo solo competitivas a nivel nacional.

8. Directivos de empresas listadas en el ranking de competitividad tuvieron actitud muy favorable en el $33 \%$ de las áreas de acción clave; medianamente favorable en el $58 \%$ y bajamente favorable en el $9 \%$, comparado con los directivos de empresas ausentes que tuvieron una actitud muy favorable en el $6 \%$; medianamente favorable en el $88 \%$ y bajamente favorable en el $6 \%$.

9. Podemos concluir que la investigación realizada pretende:

a) Concientizar a los directivos empresariales de la necesidad de incorporar habilidades y destrezas nuevas a su forma habitual de liderar las empresas, porque las aprendidas dejaron de ser útiles.

b)Cubrir vacíos de información en el área del liderazgo empresarial toda vez que el énfasis curricular, programas de capacitación y perfeccionamiento está en el área de gestión y muy poco o casi nada en el de liderazgo.

10.Finalmente, espero que esta investigación sea el inicio de otras que traten de explicar las razones del por qué, nuestro país hermoso, rico y con muchas ventajas comparativas para el turismo, sigue siendo un país desperdiciado. 